
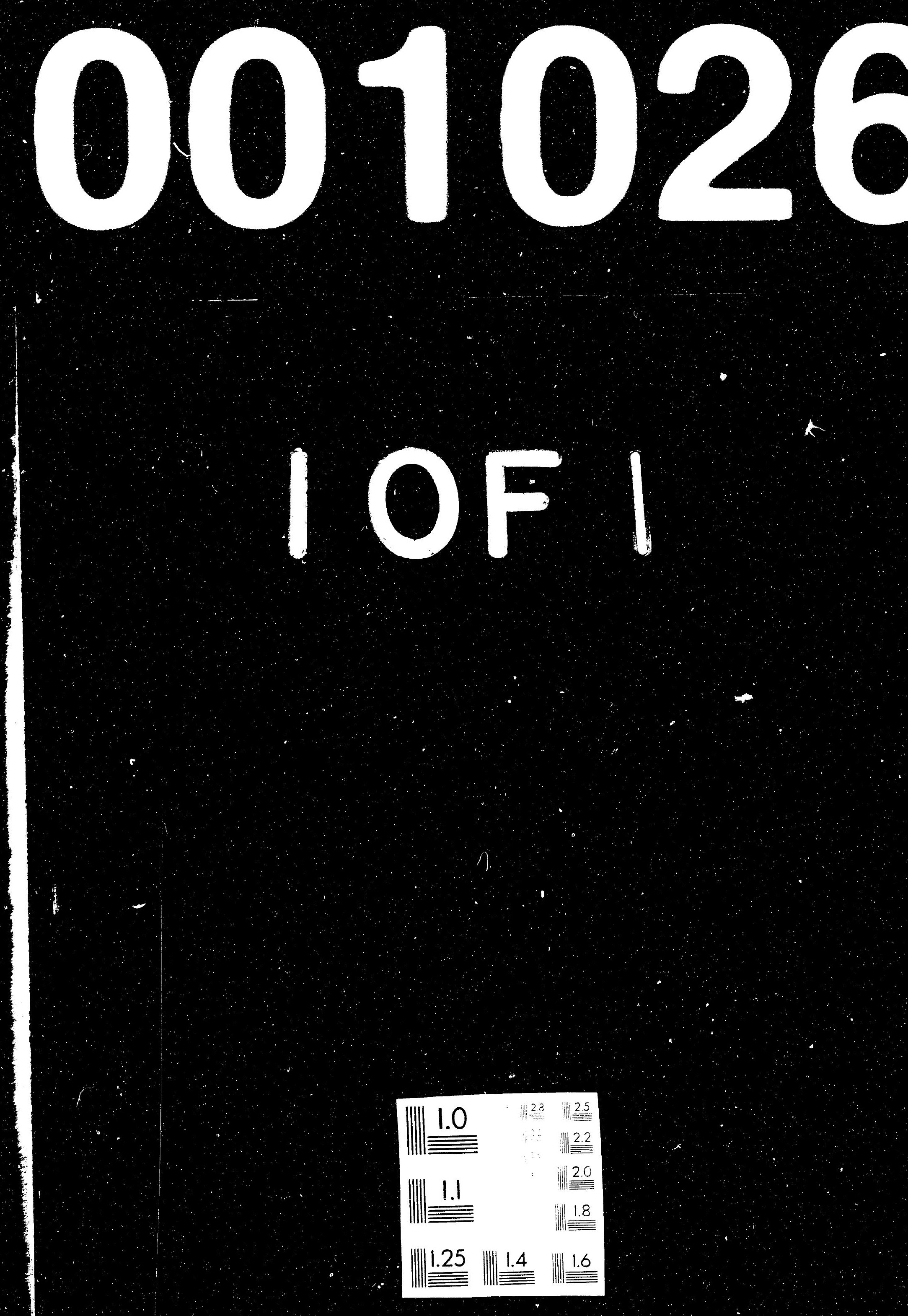


\section{DISCLAIMER}

This report was prepared as an account of work sponsored by an agency of the United States Government. Neither the United States Government nor any agency thereof, nor any of their employees. makes any warranty. express or im.plied, or assumes any legal hability or responsibility for the accuracy, $6 \mathrm{Jm}$ pleteness. or usefulness of any information, apparatus. product. or process disclosed. or represents that its use would not intringe privately owned rights Reference herein to any specific commercial product. process, or service by trade name, trademark. manufacturer. or otherwise does not necessarily constitute or imply its endorsement. recommendation. or favoring by the United States Government or any agency thereof The views and opinions of authors expressed herein do not necessarily state or reflect those of the United States Government or any agency thereot.

This report has been reproduced directly from the best available copy.

Available to DOE and DOE contractors from the Office of Scientific and Technical Information, P.O. Box 62, Oak Ridge, TN 37831; prices available from (615)576-8401, FTS 626-8401.

Available to the public from the National Technical Information Service, U.S. Department of Commerce, 5285 Port Royal Rd., Springfield, VA 22161. 
$\mathrm{DOE} / \mathrm{BC} / 14600-20$

Distribution Categorv UC-122

VISUALIZATION EXPERIMENTS ON STEAM INJECTION IN HELE-SHAW CELLS

$\mathrm{DOE} / \mathrm{BC} / 14600--20$

DE92 001026

Topical Report

\author{
By \\ Xianli Kong \\ Monouchehr Haghighi \\ Yanis C. Yortsos
}

March 1992

Work Performed Under Contract No. FG22-90BC14600

Prepared for

U.S. Department of Energy

Assistant Secretary for Fossil Energy

Thomas B. Reid, Project Manager

Bartlesville Project Office

P. O. Box 1398

Bartles:ille, OK 74005

Prepared by

University of Southern California

Petroleum Engineering Program

Department of Chemical Engineering

Los Angeles, CA 90089-1211 


\section{Contents}

List of Figures $\quad$ iv

1 Abstract 1

2 Introduction $\quad 1$

3 Experimental 3

4 Results and Discussion 4

4.1 Displacement in Horizontal Hele-Shaw Cells ................ 4

4.2 Gravity Effects . . . . . . . . . . . . . . . . . . . 8

5 Conclusions $\quad 9$

$\begin{array}{lr}\text { REFERENCE } & 10\end{array}$ 


\section{List of Figures}

1 Schematic of the experimental apparatus . . . . . . . . . . . 12

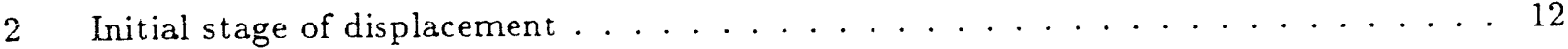

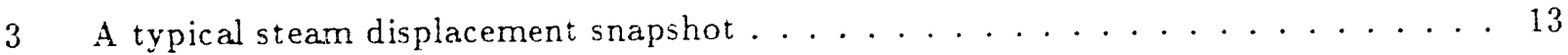

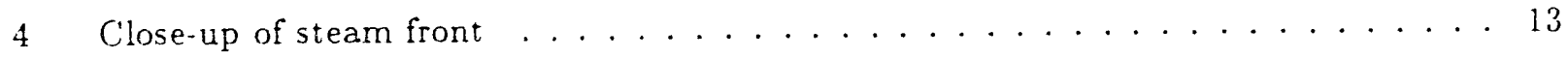

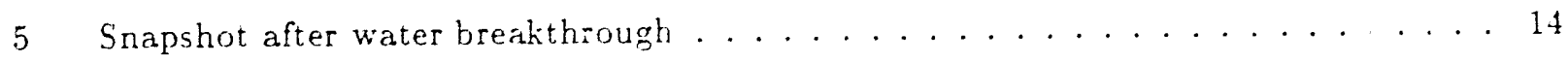

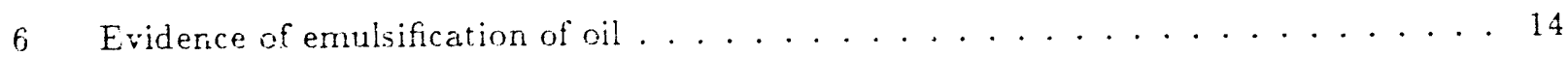

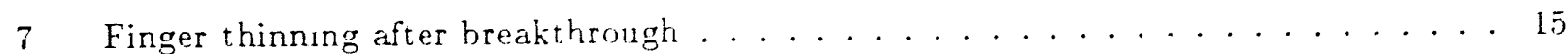

8 Typical fingering pattern for oil displacement by water . . . . . . . 15

9 Snapshot of mineral oil displacement by stearn . . . . . . . . . . 1f

if Steam zone during displacement by steam of a Long Beach crude . . . . . . . 16

11 A different snapshot of steam zone displacement of Long Beach crude oil . . . . . . 17

12 Close-up of steam zone during steam displacement . . . . . . . . . 17

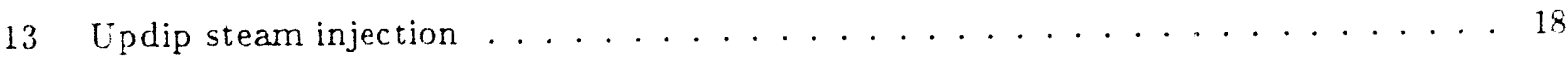

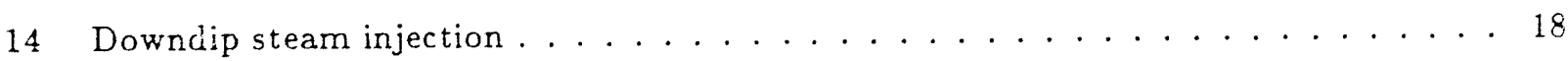

15 Steam displacement in a veri.ical cross-section . . . . . . . . . . 19

16 Close-up of stram zone during displacement in a vertical cross-section . . . . . . 19

17 Snapshot after water breakthrough . . . . . . . . . . . . . 20

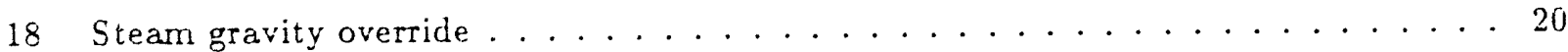




\title{
VISUALIZATION EXPERIMENTS ON STEAM INJECTION IN HELE-SHAW CELLS
}

\author{
X. Kong, M. Haghighi and Y.C. Yortsos
}

\section{Abstract}

Flow visuclization experiments have been successfully employed in reservoir engineering research for many years. They involve 2-D geometries in transparent Hele-Shaw cells and glass micromodels. Although much work has been done on immiscible flows(drainage or imbibition), visualization of steamfloods, which constitute a major part of current EOR methods, has not been attempted to date. In this paper, we present experimental results on steam injection in a transparent, pyrex glass Hele-Shaw cell. Both synthetic (Dutrex 739 ) and natural heavy oils were used under a variety of conditions, including effects of gravity.

The experiments were conducted at low pressure. Results obtained demonstrate the interplay between steam injection, steam condersation. viscous fingering, heat transfer, gravity and steam distillation effects. The experiments revealed that steam fronts are neither smooth nor flat, but undergo constant rearrangements as a result of condensation and injection. These dynamics are substantially different from those in at typical immiscible displiacement. The injected steam was generally found to follow the path of the condensed water. The latter set the general displacement pattern, which in the case of heary o! was highly firgered. We also identified a rather unusual viscoelastic response of the displaced heavy oils.

\section{Introduction}

Flow visualization experiments have been successfully employed in reservoir engineering research for many years $[3,6,11,17,18 j$. Typically, they make use of transparent Hele-Shaw cells, glass bead 
packs and glass micromodels. Although such geometries lack important 3-D aspects and particularly they do not accout for effects of gravity in the case of a horizontal arrangement, they are nevertheless valuable for the insight they offer on the micromechanics of the displacement. This is particularly important for displacement processes in constricted pore geometries, where an accurate description of the dynamics of the moving interfaces is I,aramount to a proper understanding of the process.

Most of the visualizatior. work has been done on simple immiscible displacements (drainage or imbibition). A great deal of valuable information has been obtained regarding the various regimes thai govern these processes, such as percolation, DLA (Diffusion-Limited-Aggregation), and other aspects of viscous fingering [12]. Studies with micromodels have been instrumental in identifying the pertinent flow mechanisms, particularly in secondary imbibition. Some visualization experiments with glass micromodeis have also been carried out to study more complex phenomena, such as solution gas-drive, foam propagation, condensing-gas dirive and other applications $(1,4,5,14,19)$. An excellent recent summary can be found in [2].

Surprisingly, visualization of steamfloods, which constitute a $r$ ijor part of current EOR methods for heavy oil, has not been attempted to date (although a preliminary investigation was indeed conducted in our laboratory several years ago). Reasons for the lack of success in this direction include the difficuities associated with an adequate control of the heat transfer and operational problems at higher temperatures and pressures. In a some what related context, the application of CT scanning to steamfloods in sandpacks was recently proposed with encouraging preliminary results 7 . Flow imaging using CT scanning accounts for important 3-D effects. However. the scale of resolution is still too large to allow for a meaningful pore-level analysis, although important laege scale heterogeneity effects can indeed be detected. At present, direct fow visualization appears to remain an essential and inexpensive tool for studies at the pore-level.

Even in the absence of heat transfer control, steam displacement visualization can be very valuable. For example, while much work has tren done on steamfloords in laboratory cores and on partly scaled models $8.15,16$, the results obtained are typically of the input-output type and provide very limited understanding of the interactions at the pore-level. A thorough investigation of the latter is important for the validation of many premises used in current theories, for the refinement and improvement of models, for instance those pertaining to relative permeabilities and capillary pressure, and for process simulation. It should be pointed out that the current state of the 
art in thermal recovery relies on the direct application of two-phase flow concepts from immiscible displacement analogues [13], the validity of which. however, for condensing-evaporating drive, is quite questionable.

Motivated by the above, we have undertaken experimental studies with a main objective the visualization of steam injection processes in Hele-Shaw cells and in glass micromodels. The study of Hele-Shaw geometries is expected to shed light on the displacement of heavy oils by steam in planar geometries. To some degree, this geometry parallels that of a fracture, hence the study would also find direct application to fractured systems. More generally, flow in Hele-Shaw cells provides many clues about flow behavior in porous media. It should be recalled that flow in Hele-Shaw cells at low Reynolds numbers is potential and can be approximated by Darcy's law, which governs porous media flow, although in the absence of microstructure ("noise"). Hence, Hele-Shaw studies of stearnfloods offer a good approximation of condensing/evaporating flows in "porous media" geometries. On the other hand, because of the lack of microstructure, which is an integral nart of porous media, the analogy between Hele-Shaw and porous media displacement is also tenuous. This deficiency can be partially remedied by studies in glisss micromodels, which allow for effects of pore structure to be investigated in great detail. Surh an investigation will be reported in a future communication.

This paper is organized as follows: First, a brief description of the experimental procedure is presented. Results of visualization experiments are subseaquently discussed. Two different geometries are analyzed, one horizontal and another vertical, in order to isolate gravity effects.

\section{Experimental}

The Hele-Shaw cell used for steam displacement was constructed from pyrex glass. The cell was of dimensions $24.5 \mathrm{in} \times 12 \mathrm{in} \times .03 \mathrm{in}$. and consisted of two glass plates of $1 / 2$ " thickness. Three types of oil were used, a synihetic oil (Dutrex i39), taken as a representative of heavy oil. a mineral oil, taken as a representative of light oil, arid a Long Beach crude oil. The mineral oil used was Newtonian, with a room temperature viscoity of $189 \mathrm{cp}$, while both the Long Bearh crude oil and the synthetic oil exhibited no:-Newtonian behavior with a room temperature shear viscosity of $1.35 \times 10^{4} \mathrm{cp}$ and $10^{5} \mathrm{cp}$, respectively. The shear viscosity for Dutrex 739 was significantly reduced by an increase in temperature 8: A similar sensitivity was expected, but it was not measured. 
for the Long Beach crude. Non-Newtonian rheology, although complicating the interpretation of experiments, is certainly a prominent, although typically neglected, feature of heavy oils.

Variable water injection rates and temperatures were used, typically in the range $0.1-5 \mathrm{cc} / \mathrm{min}$. Injection temperatures fluctuated to within a few ${ }^{\circ} \mathrm{F}$ around a mean value of $250^{\circ} \mathrm{F}$. Ir most runs, the injected steam was superheated. The Hele-Shaw cell *as not insulated or otherwise equipped with heat loss control, which occured by heat conduction through the glass to the surroundings. The lack of heat transfer control certainly presents important problems that may affect the quantitative, although not the qualitative, analysis of our results. A separate, but equally important, problem regards the low injection pressure typically used (in order to prevent fracturing of the glass). We are currently experimenting with ways to resolve both these problems. More than 30 runs were conducted. Most of the experiments were run with the cells in the horizontal position. Effects of gravity were investigated by tilting t' e cell at various angeles and also by carrying injection in the configuration of a planar vertical cross-section. A schematic of the experimental set up is shown in Figure 1.

\section{Results and Discussion}

We shall discuss in the following two sets of experimental results pertaining to: (i) Displacement in horizontal Hele-Shaw cells and (ii) Effects of gravity.

\subsection{Displacement in Horizontal Hele-Shaw Cells}

We consider as base case the displacement of Dutrex 739 by steam at the rate of $3 \mathrm{cc} / \mathrm{min}$ and an injection temperature of $230^{\circ} \mathrm{F}$. In the subsequent pictures, taken from a still videotape. displacement is from left to right. One injection and one production ports were used. In the colored pictures, red is the color of the original oil, and bright white is steam. Condensed water typically flow:s between residial yellow oil films attached to the two glass plates and left behind after wator displacement.

Figure 2 shows the initial part of the displacement. Due to the rapid heat losses and the contact with the initially cold oil, steam is shown to condense rapidly. Thus, the original displacement of oil is by condensed water only. Because of the unfavorable mobility contrast, this displacement 
is unstable [20] and produces viscous fingers in a manner very similar to the case of isothermal displacement, although the overall pattern is slightly different. Nonetheless, repeated tip splitting was observed, as is common with highly unstable displacement [10]. We point out that the pattern luid by the advancing condensed water is of crucial importance, because it dictates the paths to be followed by the injected steam. After a certain period of injection, a rather irregular steam zone is established near the injection port (Figure 3). Vapor and liquid phases can be visually separated. Upon displacement of oil, liquid water is covered on both sides by yellow, residual oil films which coat the glass plates. Upon contact with vapor, these films rapidly diminish in thickness and eventually disappear, perhaps as a result of a steam distillation mechanism. A clnse up of the steam zone is shown in Figure 4. One can distinguish traces of what appear to be light oil comporients. Even after the glass plates are clean, vapor and liquid can be visually separated by the meniscus, the motion of which can be clearly followed.

Most interesting are the shape and properties of the steam front. We recall that in a typical immiscible displacement in a Hele-Shaw cell, interfaces advance smoothly provided that the plates are smooth. This was indeed the case for the displacement of oil by the advancing condensed water (Figure 5). The thin films of oil left behind are predicted from Bretherton's theory for displacement [9], which postulates that their thickness increase with an increas in the capillary number $N_{c a}(=$ $q \mu / \gamma)$. The dynamics of vapor-liquid interfaces are quite different, however. Typically, two kinds of water vapor-liquid interfaces were observed, a steam-oil and a steam-water interface (Figure 5). The steam-oil front was almost stationary and moved very slowly (if at all). Disconnected and trapped steam bubbles were frequently observed. By contrast, the steam-water interace was in a state of perpetual fluctuation, which eventually resulted into a net but slow advancement. This was explained as follows:

The advancement of the steam front led to a rapid condensation of a sizeable part of the steam zone, as a result of heat losses. Shortly therafter, this was followed by a rapid burst of vaporinflux, which essentially restored to vapor occupation the previously condensed part. This cycle of advancement-vapor condensation-vapor replacement was repeated continuously and appeared to be the general mechanism for the growth of the steam zone. In no instance did we observe a smooth frontal displacement of the typical water-oil intersace. Also, in contrast to what typically assurned, steam fronts were neither smooth nor "flat", but they had a finger-like appearence, as they followed 
the flow paths of the condensed water. This complex process is of course controlled by heat transfer, vicosity reduction, injection rates and pressure, the end result being quite different than ordinary Hele Shaw displacements. Indeed, it is possible that condensation and vapor growth phenomena in the above cycles are rapid enough for inertia effects not to be negligible. This complex mechanism is currently under investigation.

Water breakthrough occurs when the fastest among the competing fingers reaches the production end. Important observations during this period were the following: Steam flowed mostly along the paths connerted to the production well. Water fingers connected to the steam zone that did not breakthrough, occasionally became disconnected from the steam zone due to condensation events. Flow of steam was not smooth but involved the condensation -advancement cycle. During this process, substantial emulsification of the oil also occured (Figure 6). After breakthrough, a large fraction of the oil produced was in the form of water emulsion. We suspect that emulsification was enhanced by the following rather unusual rheological response of Dutrex. Soon after water breakthrough, the connected finger started to continuously thin, until it eventually fragmented at one or several points and lost connection to the producing port (Figure 7 ). A different finger then started growing following a usual displacement process, until breakthrough of that path was also reached. Socn after, the process of thinning commenced, once again, to follow the previous route until disconnection and so on. These phenomena are not due to steam injection, but they are attributed to the particular oil, as they were also observed during an ordinary waterflood.

A possible explanation for this behavior can be provided if we assume that Dutrex 739 is yiscoelastic. Before water breakthrough, the fluid pressure is relatively high due to the high viscosity. Upon water breakthrough, the oil responds to the resulting pressure decrease by expanding following a relaxation, time-dependent process. This results into the thinning and shrinkage of the producing water finger until total disconnection occurs. The process is then repeated. This rough qualitative argument explains the gross behavior observed, although for a more convincing interpretation, a model is necessary.

A comparison between steam and cold water displacement is shown in Figure 8 for the same mass injection rates. Typical finger patterns before breakthrough show the characteristic tip-splitting. Upon breakthrough, the same response previously described sets in. Significant differences with the steam injection runs involved the presence or residual oil films and the lack of emulsification in the 
case of water injection. Effects of injection rate were also considered, by carrying a steam injection run at the lower rate of $1 \mathrm{cc} / \mathrm{min}$. As anticipated, the decrease in the rate results into a smaller steam zone area, which did not propagate significantly far into the cell. Otherwise, phenomena qualitatively similar to the previous were observed.

For comparison, the results of steam displacement of light (mineral) oil at the same rate of 3 $\mathrm{cc} / \mathrm{min}$ and a iemperature of $230^{\circ} \mathrm{F}$ are shown in Figure 9 . Several significant differences $w$ ith the heavy oil were noted: The degree of tip splitting was considerably less, as anticipated due to the lesser viscosity contrast in the light oil case. No significant residual oi' films were detected in the displacement by either water liquid or by steam. This observation was verified by the cold water injection experiments also. In contrast to the heavy oil case, the steam front did not necessarily follow the path of the condensed water fingers. Instead, the steam zone expanded almost uniformly. This behavior can be attributed to the higher mobility of the light oil, and it is consistent with currently available theories. The kehavior of the mineral oil was Newtonian throughout the process. Upon breakthrough, the water finger width remained essentiaily constant and provided the main flow path for the injected steam.

Steam displacement of the Long Beach crude oil resulted into a behavior qualitatively similar to the displacement of Dutrex 739. Severe fingering by condensed water (Figure 10), residual oil films after waterflood (Figure 11), steam front oscillation, propagation of steam zone along the condensed water path (Figure :1) and finger thining after breakthrough were all observed. It appeared that the crude oil shared with Dutrex 739 a similar non-Newtonian rheology. A significant difference was noted, however, regarding water vapor-oil interaction. The almost instantaneous removal of the residual cil film upon steam contact, observed during displacement of Dutrex 739 , did not occur in the case of crude oil. Instead, a process resembling extraction of light ends (perhaps steam distillation) set in at the vapor-oil interface (Figure 12). The extracted components did not parti ion in the water phase, but were instead convected along with the flowing vapor. The extraction process, continued for the duration of the experinents and appeared to be a primary mechanisin for the recovery of the cruile oil. 


\subsection{Gravity Effects}

The next set of experiments investigated effects of gravity following twe different geometrical configurations, one with the Hele-Shaw cell tilted at a small angle with respect to horizontal, and another with the cell rotated paralld to the gravity vector (vertical cross-section).

In the first configuration we probed effects of formation dip. Steam was injected from the bottom (updip) or from the top (downdip). For updip injection, steam displacement occured along a rather narrow strip, the density difference acting to destabilize the front. The oscillation phenomena of the front were well pronounced and steam zone breakthrough occured in a short time (Figure 13). In direct contrast, a flat and stable steam front was observed in the case of downdip injection (from top). This front advanced very slowly, due to the heat loss, most of the displacement occuring by the condensed water (Figure 14). Both these observations are generally consistent with conventional theories on the effect of gravity on displacement fronts.

In the second configuration we probed effects of gravity override, for both Dutrex 739 and Long Beach crude oil steamfloods. The most significant difference with the prevrious involved the interplay fetween gravity, condensation and heat transfer. Typically, the injected steam migrated upwards to form a rather stationary steam zone. Condensed water fowed downwards in the direction of a water finger at the bottom of the steam zone, which developed at the onset of the experiment and displaced oil towards the production well (Figure 15). Most of the oil displacement occured as a resuit of this mechanism, although the extraction process was also very much evident. (Figure 16). After water finger breakthough, steam f.Jw ensued along the finger path, much like in the case of horizontal displacement (Figure 1 7 ). As in the previous case, the non-Newtonian response of the heavy oils eventually resulted into finger thinning. Now, however, when the connection to the production part is lost, the steam zone at the top starts growing. Condensed water creates a finger originating from the upper part of the steam zone, resulting into a displacement along the top, in a mechanism similar to the horizontal case (Figure 18). After this finger reaches breakthrough, the cycle sets on again and a different branch may be selected. The process continues until the displacement is completed. We observed that the steam zone volume depends significantly on whether it is connected to a finger that has already reached breakthrough or not. In the former case, due to the prevailing lower pressure, steam zone volume is much larger than when the water finger is not at breakthrough conditions. 


\section{Conclusions}

The preliminary experiments reported above have probed a part of the complicated process oi steam displacement. One of the most interesting results, common to all runs, was the ursteady, almost flickering state of the steam front, and the mode of advancement by the cycle penetrationcondensation-restoration. This is certainly to be affected by injection rate, heat transfer and flow mobilities. Our current work is aimed at the understanding of this process.

For the low pressure, relatively high rate conditions of our experiments, injected steam was found to follow the path of the condensed water. The latter set thie general displacement pattern, which in the case of heavy oil was highly fingered. It should be evident, that this result is a consequence of the particular combination of fluid flow and heat transfer in our experiments, thus any extrapolation must be done with caution. We identified a rather unusual non-Newtonian behavior for Dutrex 739, a chemical taken to represent heavy oil,and for Long Beach crude oil. Regardless of the particular aspects of the response observed, one may reasonably conclude that the non-Newtonian rheology of many heavy oils is likely to lead to similarly complex behavior. This subject is further to be explored.

We have observed direct evidence of a steam extraction of oil components from a crude oil, a process that has direct relevance to the oil recovery. Effects of gravity were also examined. While the mode of injection (updip or downdip) was found consistent with currently available theories on frontal displacement, the detailed visualization of frontal motion revealed additional aspects. In particular, the growth of the steam zone in a vertical cross-section displacement was found to be affected significantly from the condensation and flow phenomena ahead of it. Much of this behavior is novel and requires further investigation. 


\section{References}

[1] P. Armitage and R.A. Dawe. What is the rheology of foarn in porous media? a micror lodel study. Paper SPE 18495, Presented at the SPE International Symposium on Oilfield Chemistry, Houston, TX, February 8-10, 1.989.

[2] J.S. Buckley. Multiphase displacement in micromodels. In Interfacisl Phenomena in Petroleum Recovery, Chapter 5, Marcel Dekker Inc., New York, 1990.

[3] A. Chatenever and J.C. Calhoun, Jr. Visual examinations of fluid behavior in porous media. Trans. AIME, 195:149-56, 1952.

[4] A. Chatenever, M.K. Indra, and J.R. Kyte. Microscopic observations of sclution gas-drive behaviour. JPT, pages 13-15, June 1959.

[5] A. Danesh, J.M. Peden, D. Krinis, and G.D. Henderson. Pore level visual investigation of oil recovery by solution gas drive and gas injection. Paper SPE 16956, Presented at the 62nd Annual Technical Conference and Exhibition of the SPE, Dallas, TX, September 27-30, 1987.

[6] D.C.Brock and F.M. Orr Jr. Flow visualization of viscous f.tgering in heterogeneous porous media. Paper SPE 22614, Presented at the 66th Annual Techrical Conference and Exhibition of the SPE, Oct.6-9, 1991.

[7] B.M.M. Demiral, L.M. Castanier, and W.E. Brigham. Ct imaging of steam and steam/form laboratory experiments. Paper SPE 2£644, Presented at the 66th Annual Technical Conference and Exhibition of the SPE, Oct.6-9, 1991.

[8] T.M. Doscher. Scaled physical model studies of the steam drive process. Technical Report DOE/ET/12075-1, Univ.of Southern California, 1980.

[9] F.P.Bretherton. The motion of long bubbles in tubes. J.Fluid Mech., 10:166-188, 1961.

10: G.M. Homsy. Viscous fingering in porous media. Ann.Rev.Fluid Mech., 19:271, 1987.

[11] V. Hornof and N.R. Morrow. Flow visualization of the effects of interfacial tension on dispacement. SPERE, pages 251-256, February. 1988. 
[12] R. Lenormand. Liquids in porous media. J. Phys.:Condens. Matter, 2:70-88, 1990.

[13] M.Parlar and Y.C.Yortsos. Percolation theory of steam-water relative permeability. Paper SPE 16969, Presented at the 62nd Annual Meeting of SPE, September 27-30, 1987.

[14] S. Owete and E. Brighain. Flow behavior of foarn:a porous micromodel study. SPE Reservoir Engineering, pages 315-323, August 1987.

[15] A.K. Singhal. Physical model study of inverted seven-spot steam floods in a pool containing a leoydminster type heavy oil. Technical Report PR-38, Petroleum Research Institut, Canada, November 1978.

[16] G.L. Stegmeier, D.D. Laumbach, and C.W. Volek. Representing steam process with vaccum models. Paper SPE 6787, Presented at the 52nd Arnual Technical Conference and Exhibition, Denver, October 3-12, 1977.

[17] P. van Meurs. The use of transparent three-dimensional models for studying the mechanism of flow processes in oil reservoirs. Trans.AIME, 210:295-301, 1959.

[18] R.A. Wooding. Instability of a viscous liquid of variable density in a vertiral hele-shaw cell. J.Fluid Mech., 7:501-15, 1960.

[19] X.Li and Y.C.Yortsos. Visualization and numerical study of bubble growth during pressure depletion in porous media. Paper SPE 22589, Presented at the 66th Annual Technical Conference and Exhibition of the SPE, October 6-9, 1991.

[20] Y.C.Yortsos. Instabilities in displacement processes in porous media. J.Phys.: Condens.Matter, $2: 443-448,1990$. 


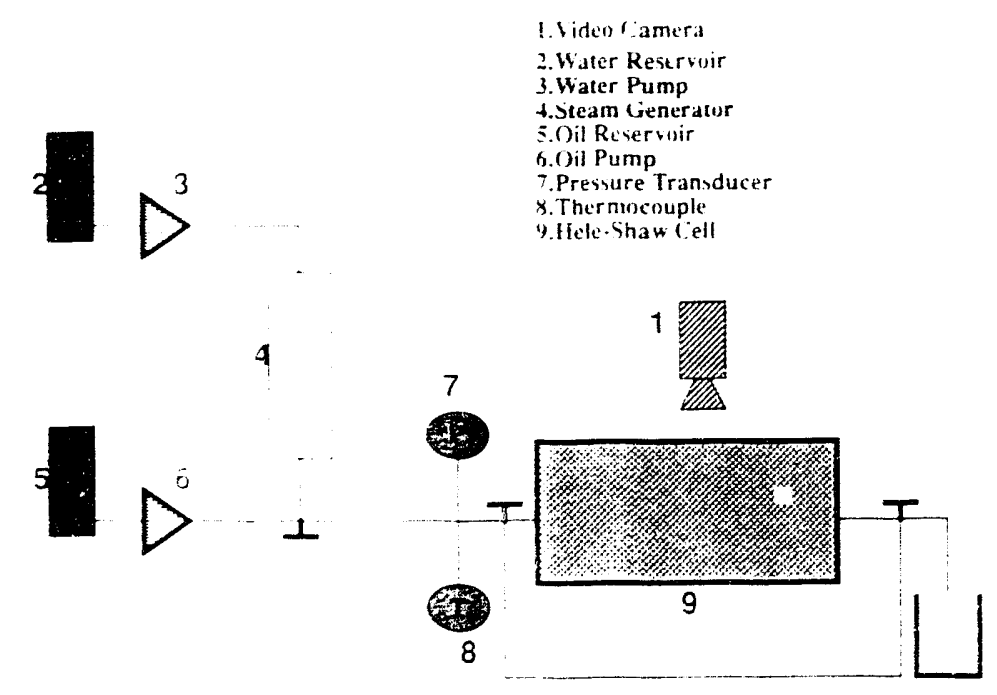

Figure 1: Schematic of the experimental a.paratus

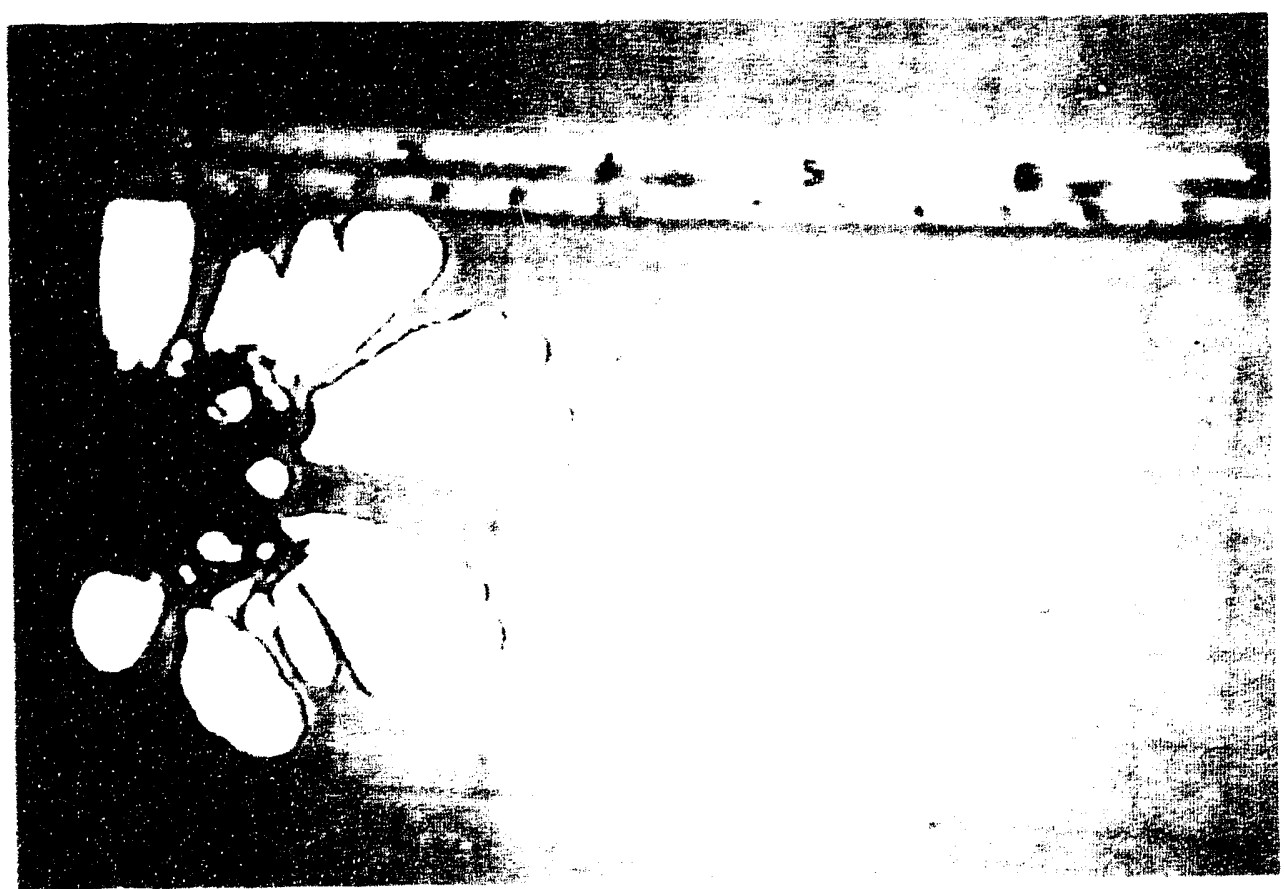

Figure 2: Initial stage of displacement 


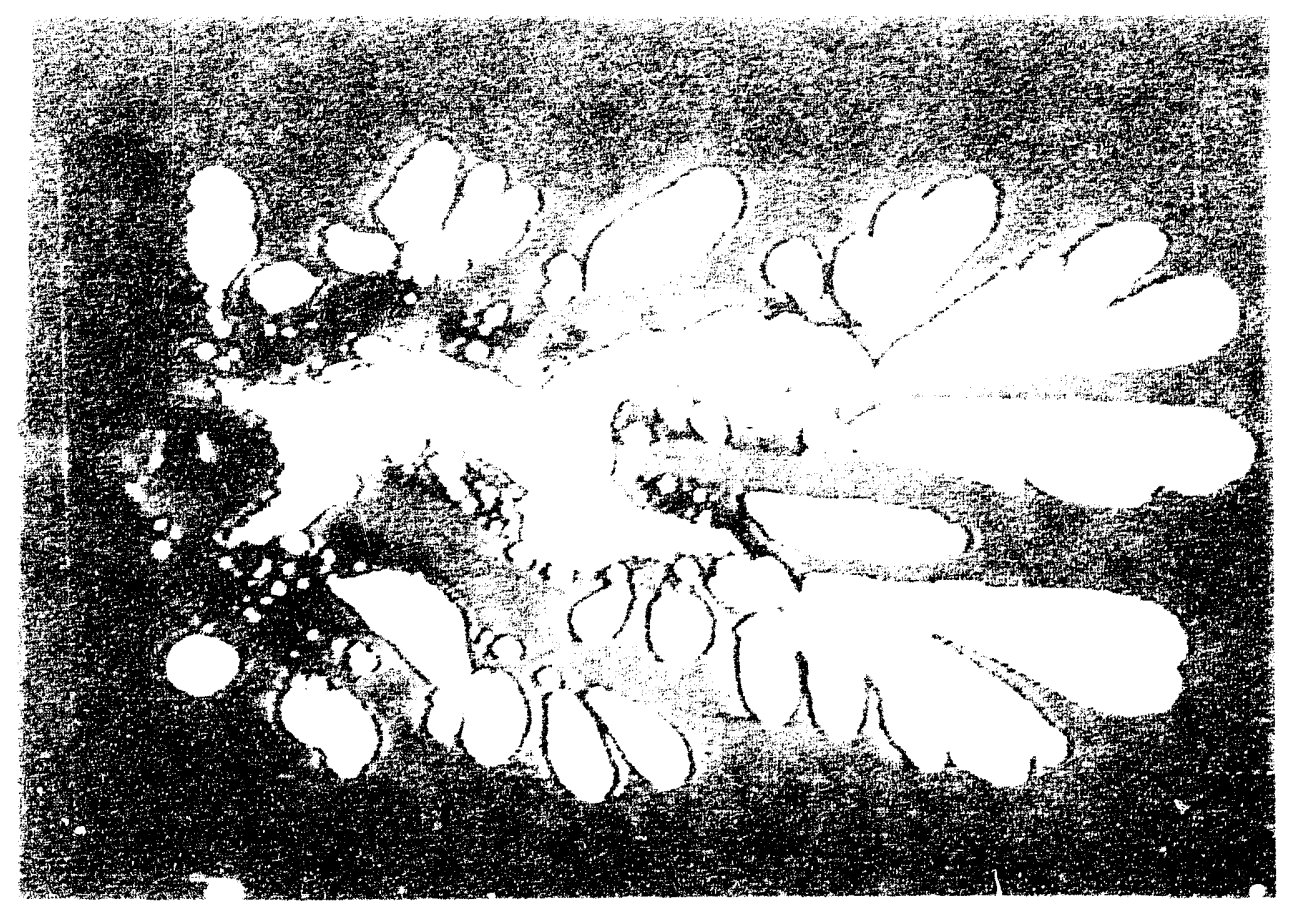

Figure 3: A tupical steam displacement snapshot

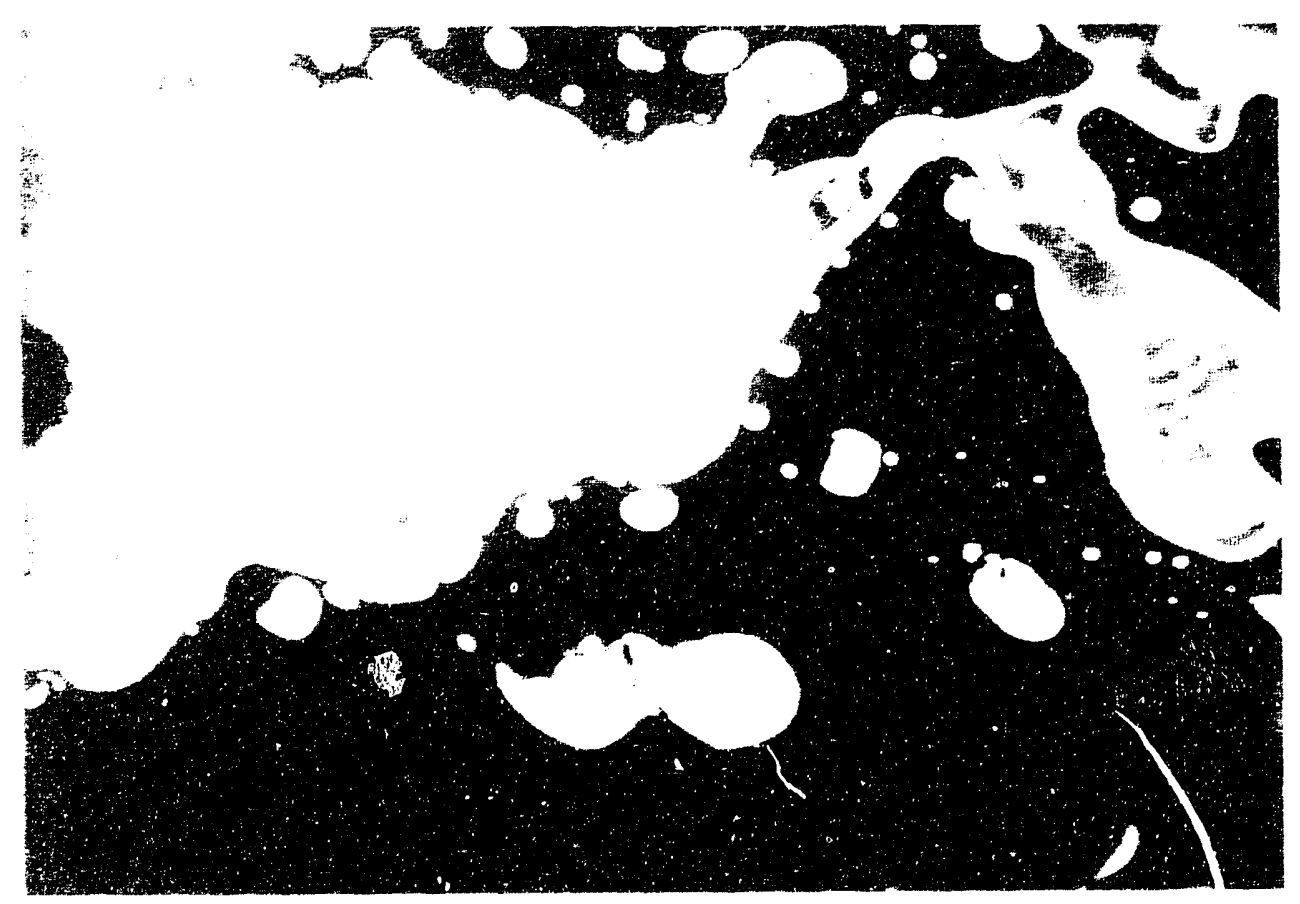

Fignis 4: Cloce-up of stame front 


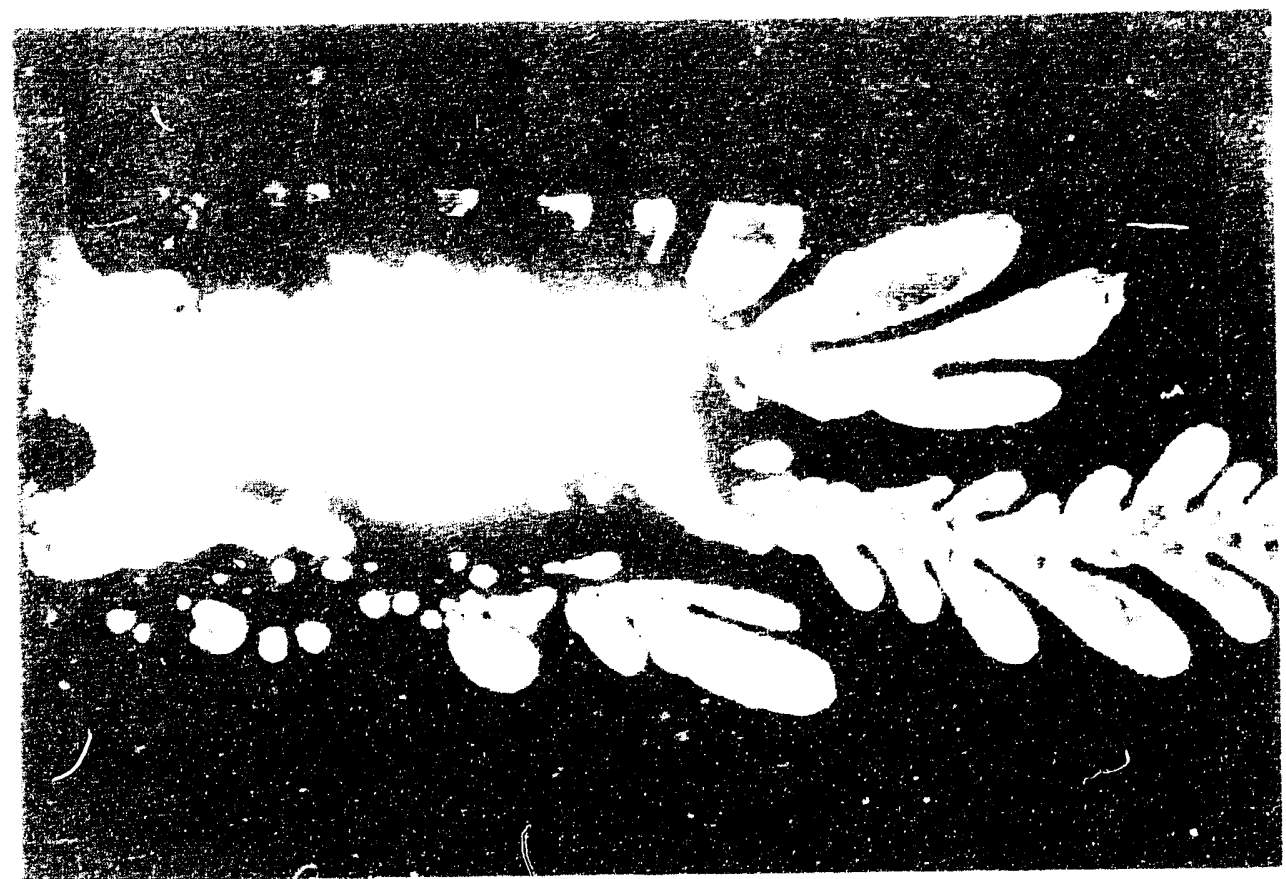

Figure j: Snaphot after water breakthrough

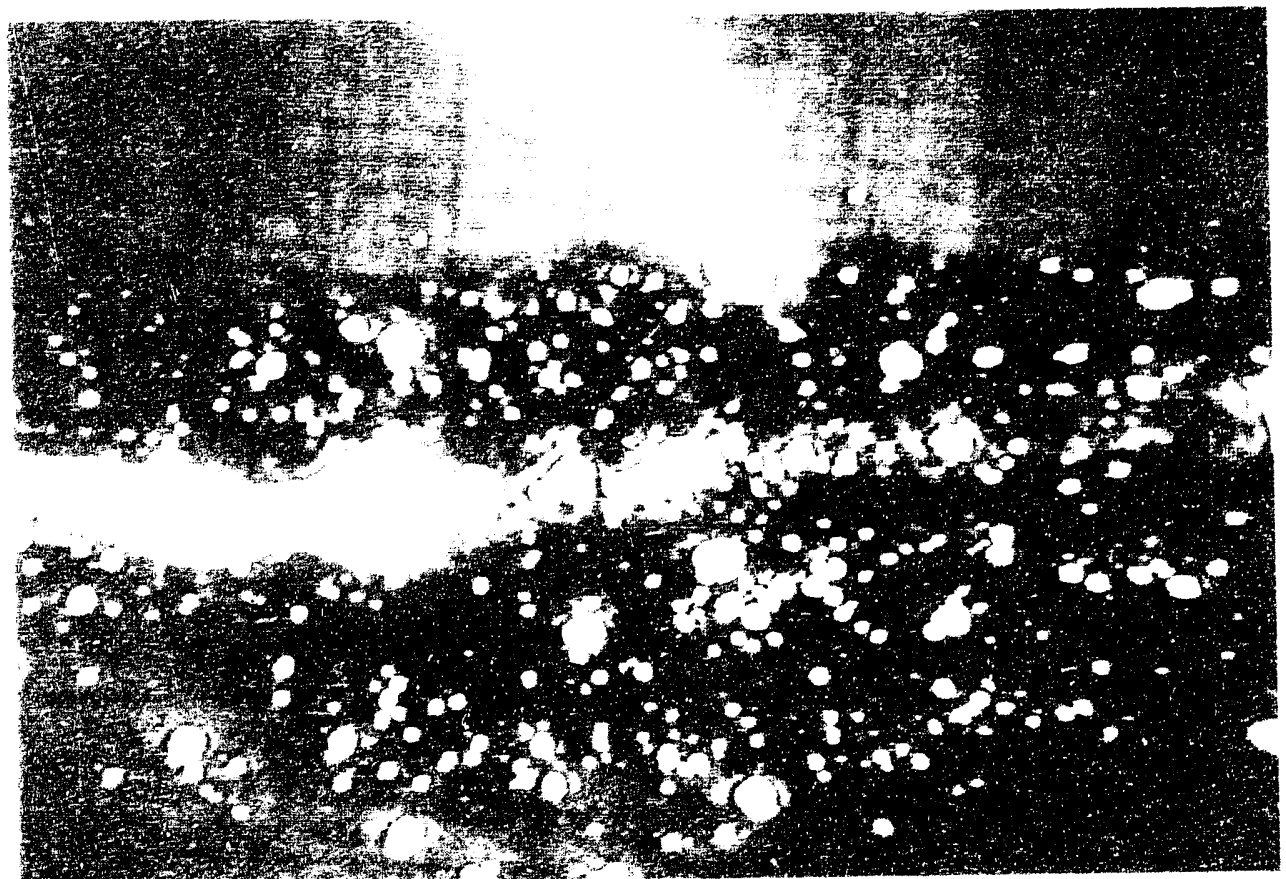

Figure 6: Evidence of emulification of oil 

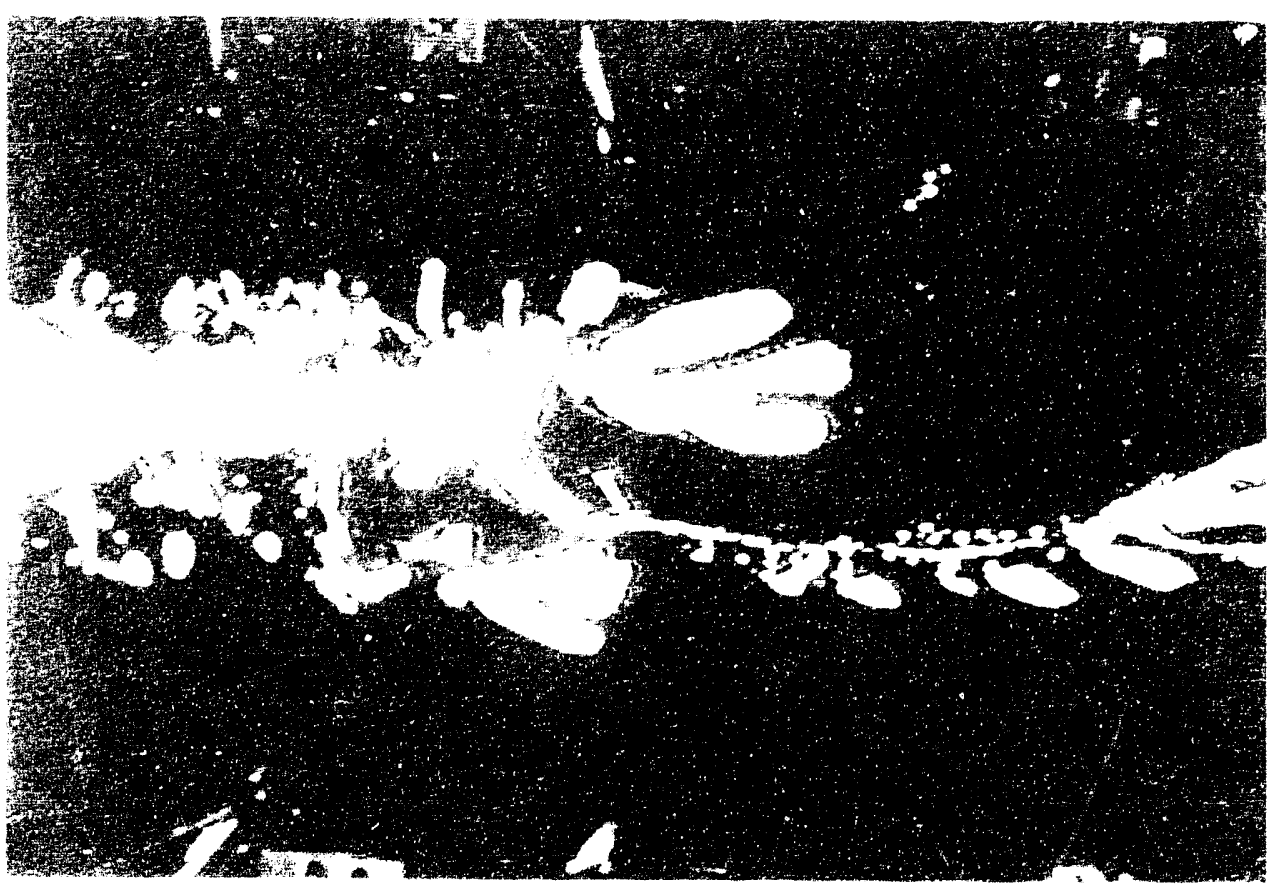

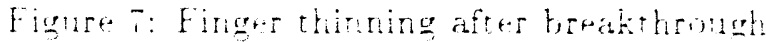

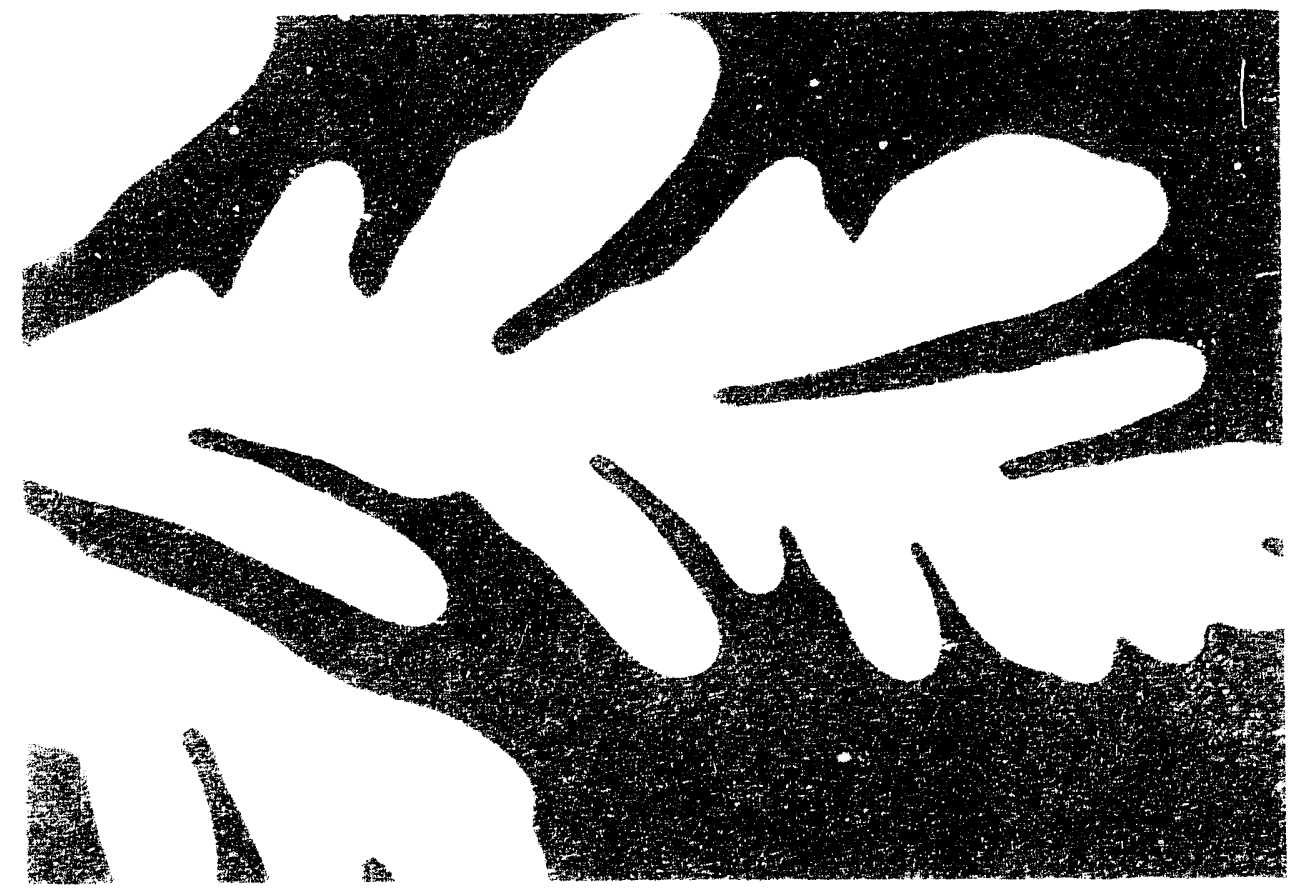

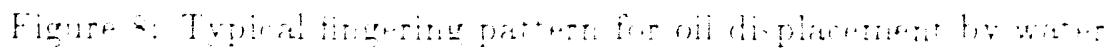




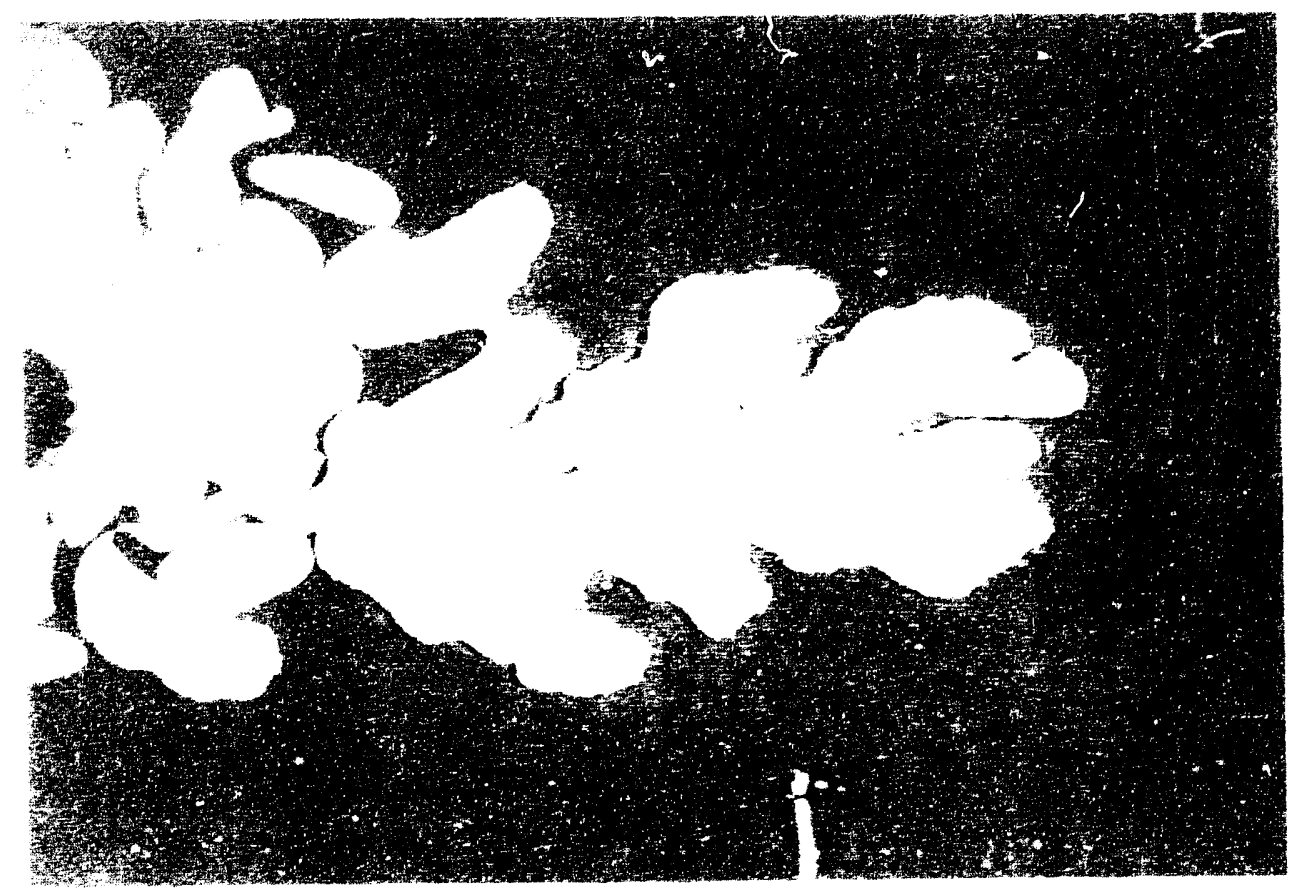

Fienes 9: Sraphot of mineral oil displacment by - want

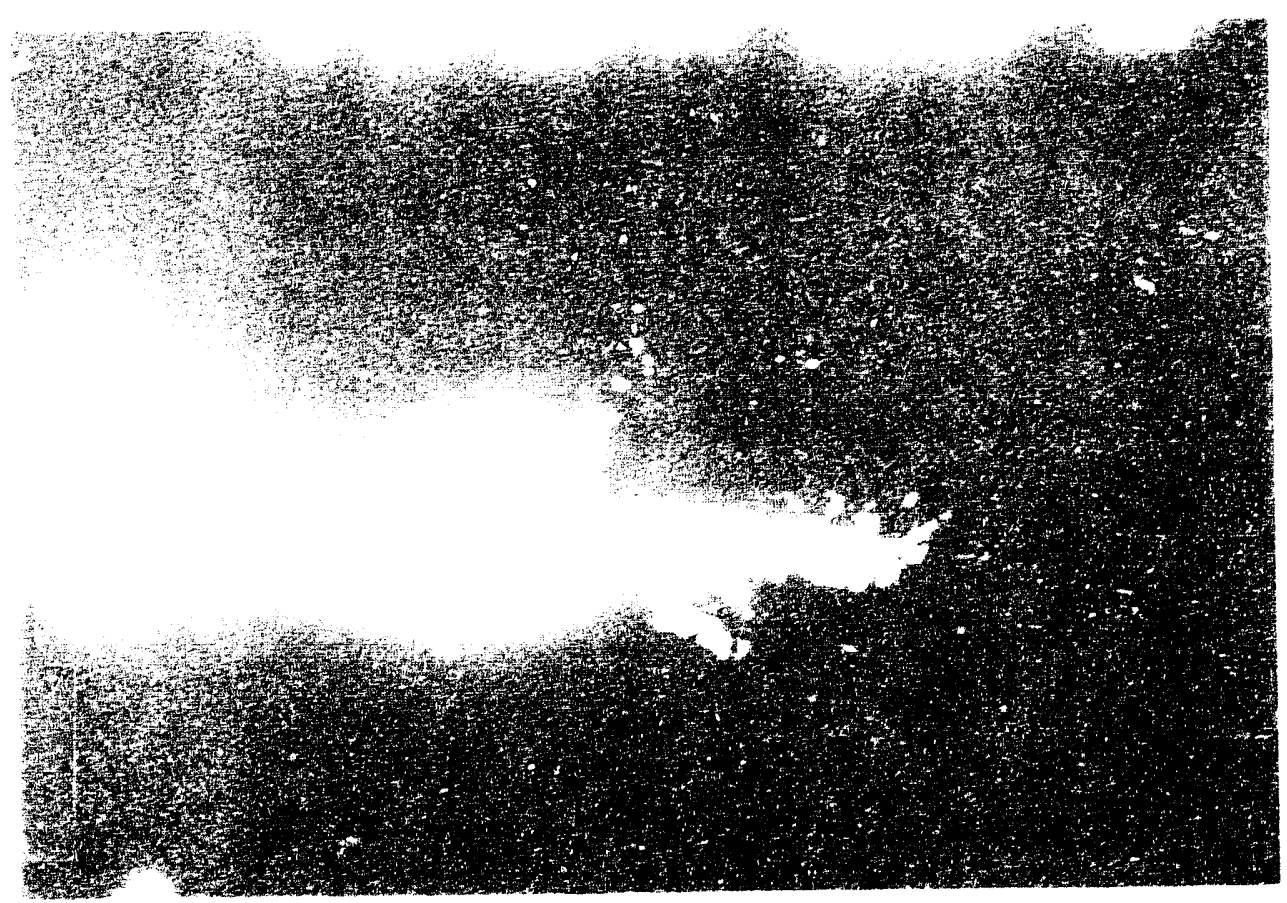

Figne la: Steam zone during displacentent by steam of a long Beach crude 

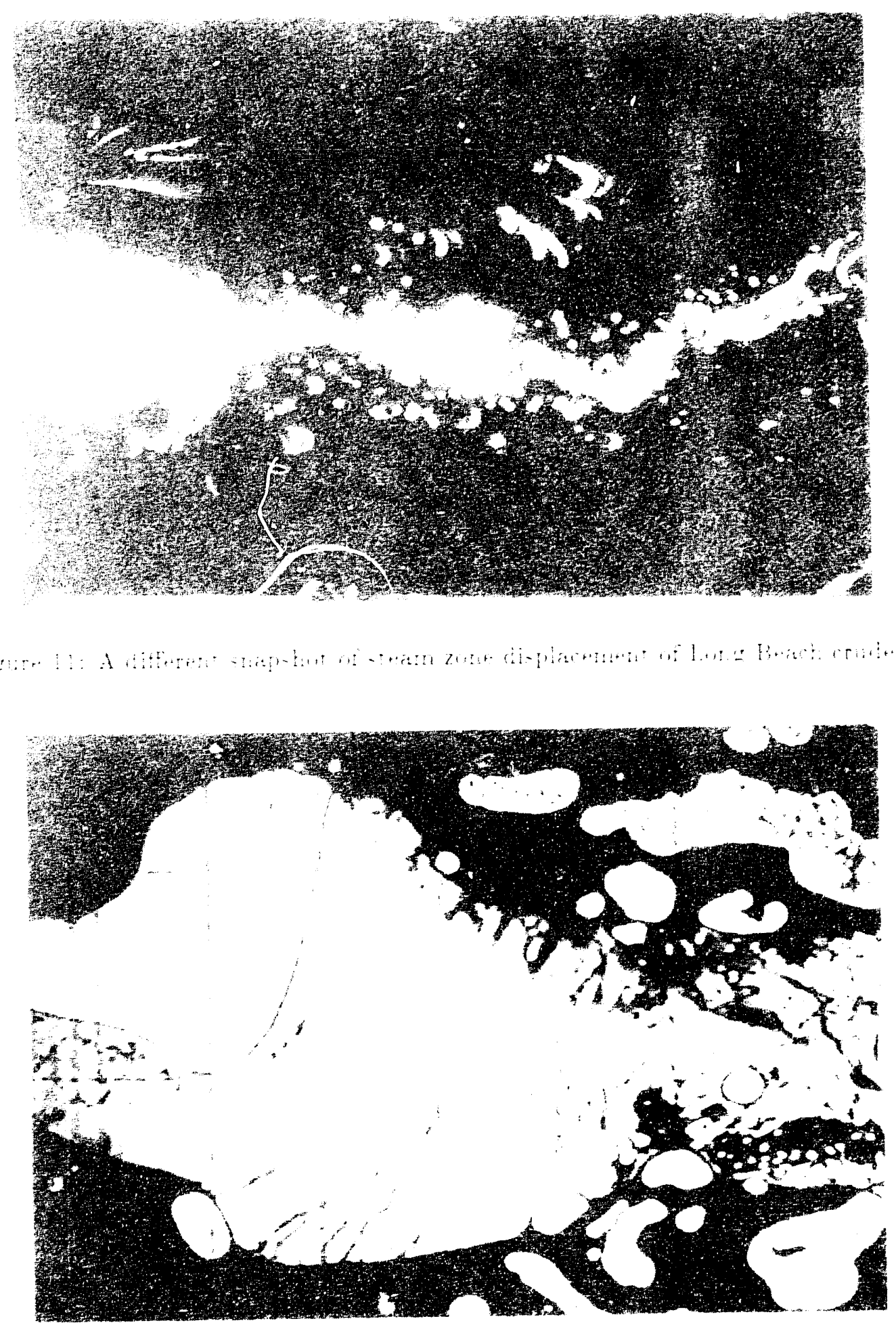

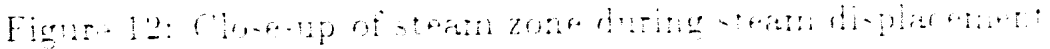




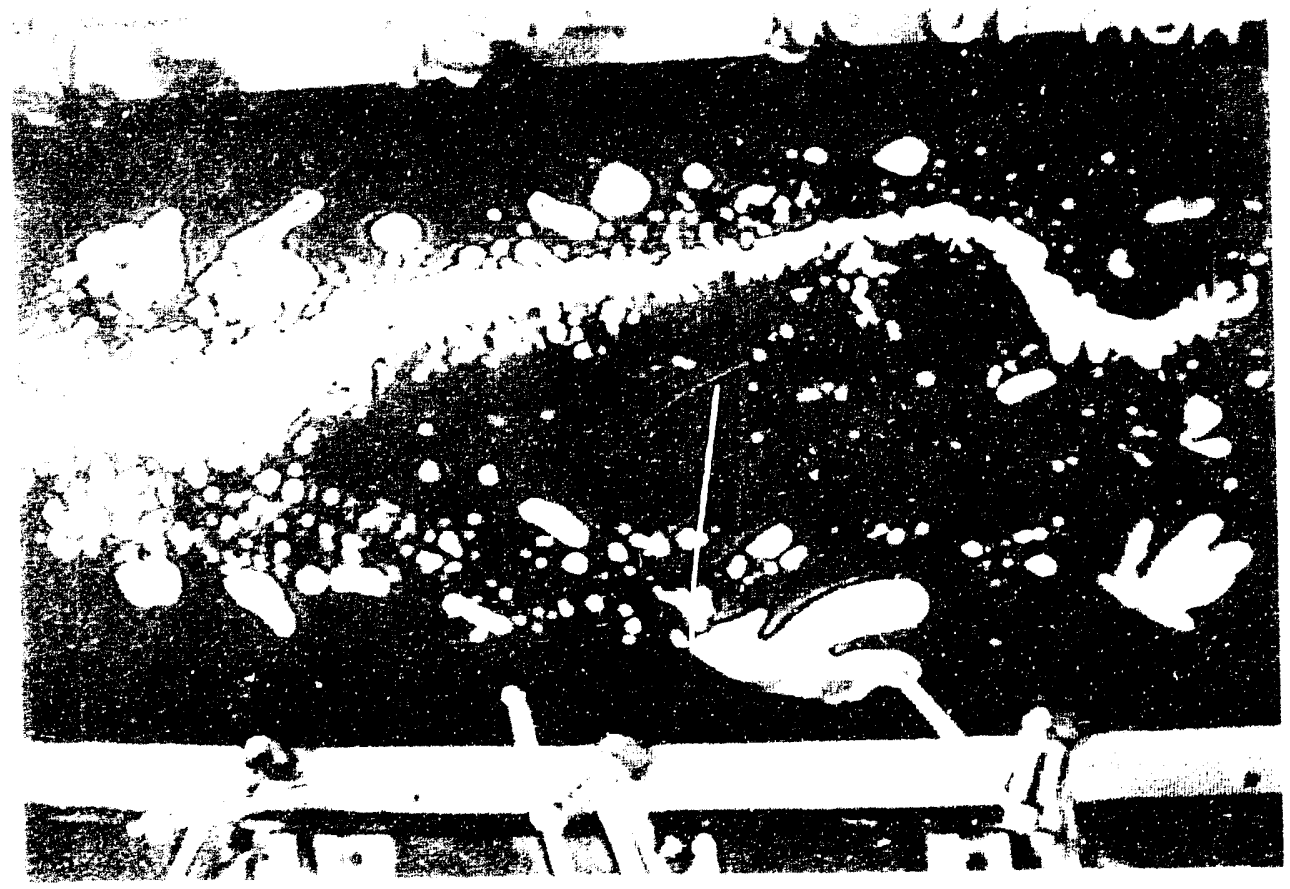

Figure 13: Tprlip steam injertion

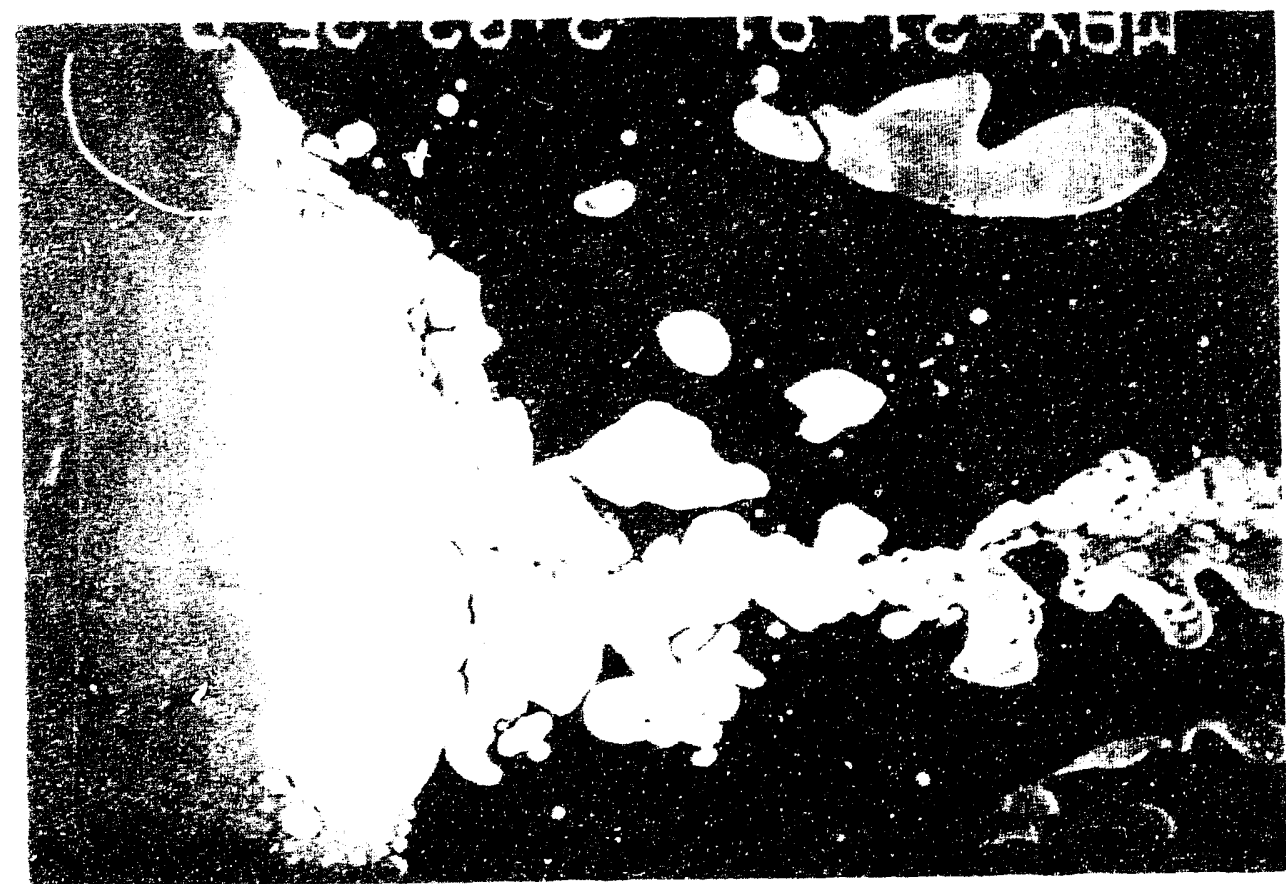

Figure 14: Downdip steam injection 

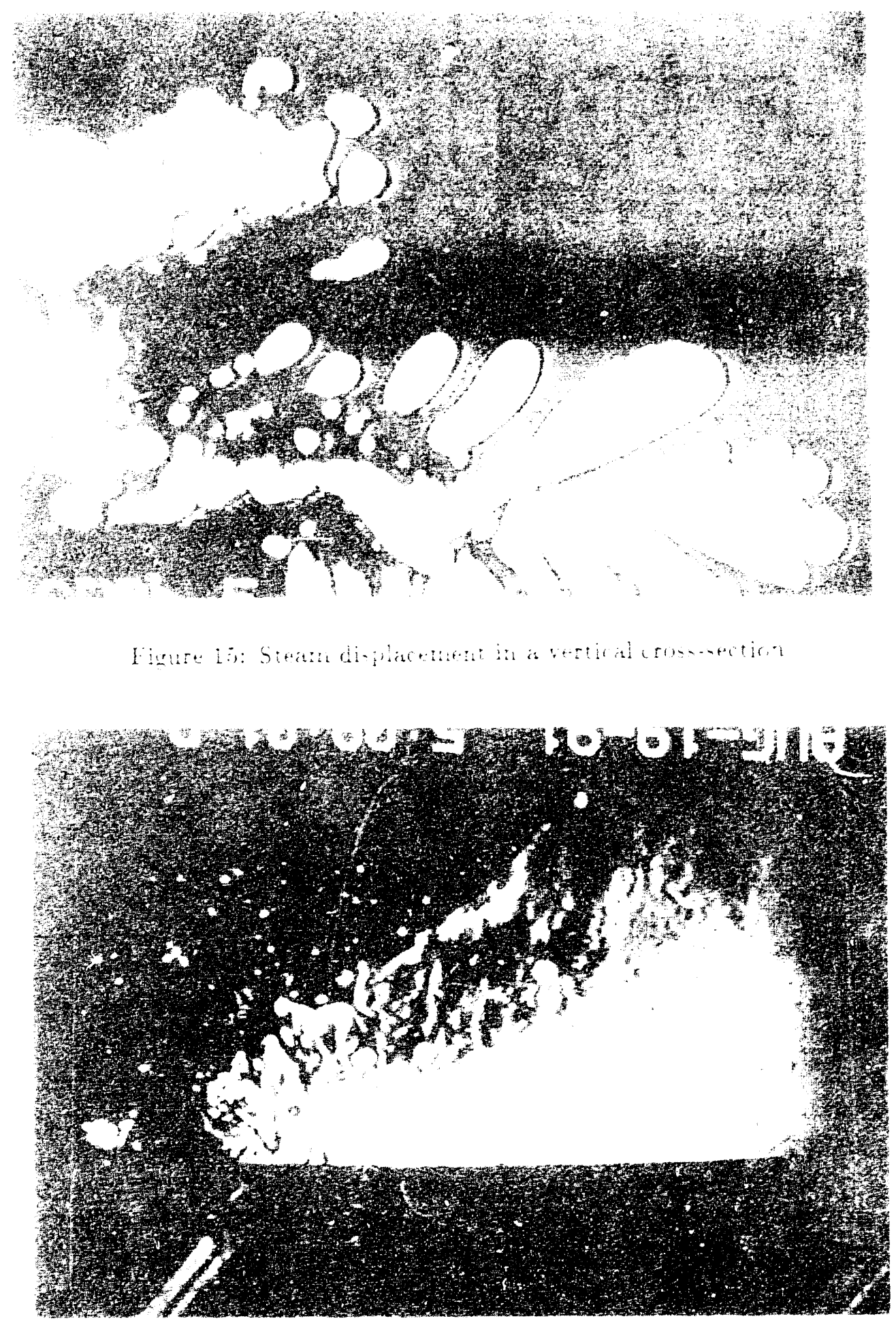

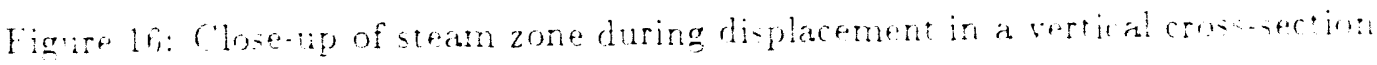




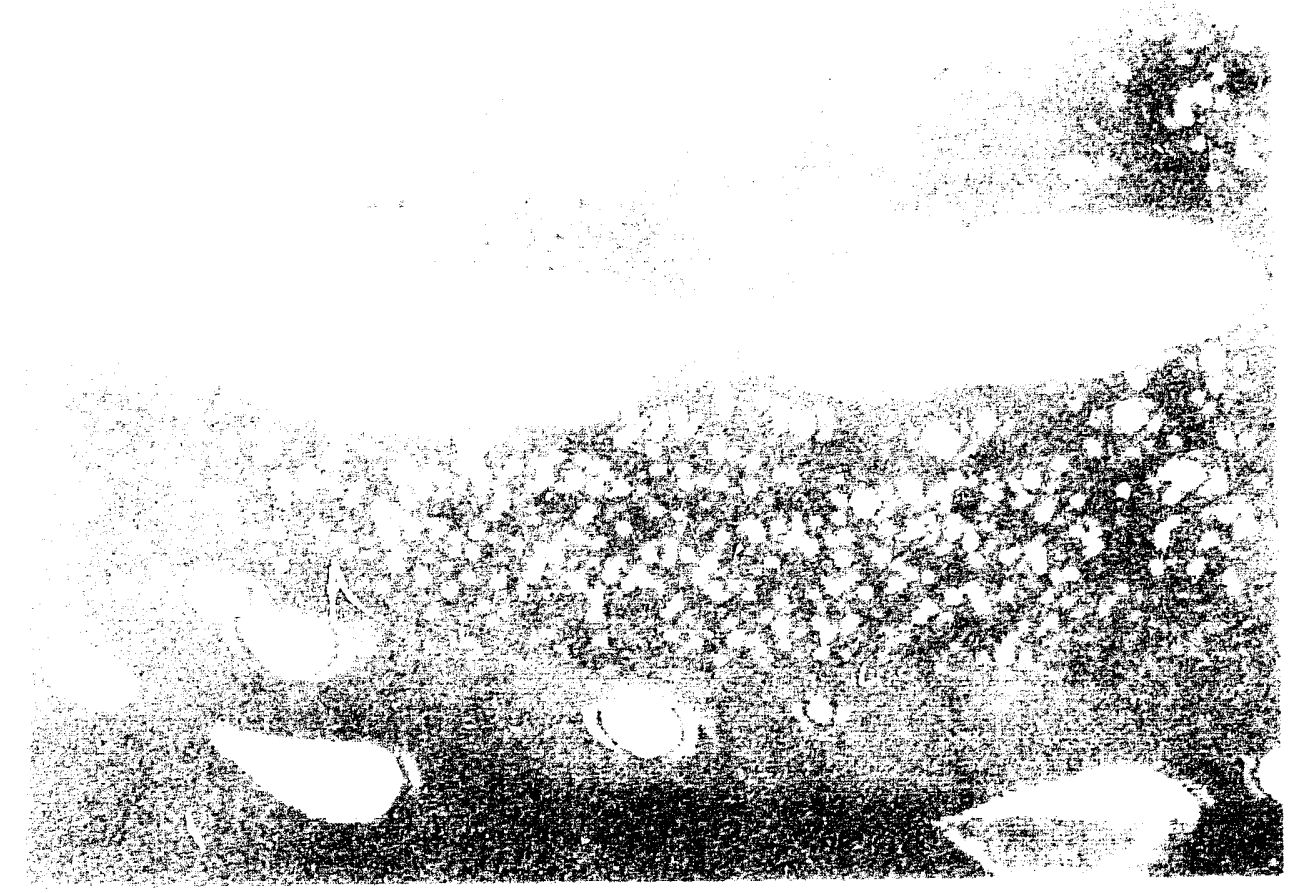

Figure 17: Snapshot after water breakthrough

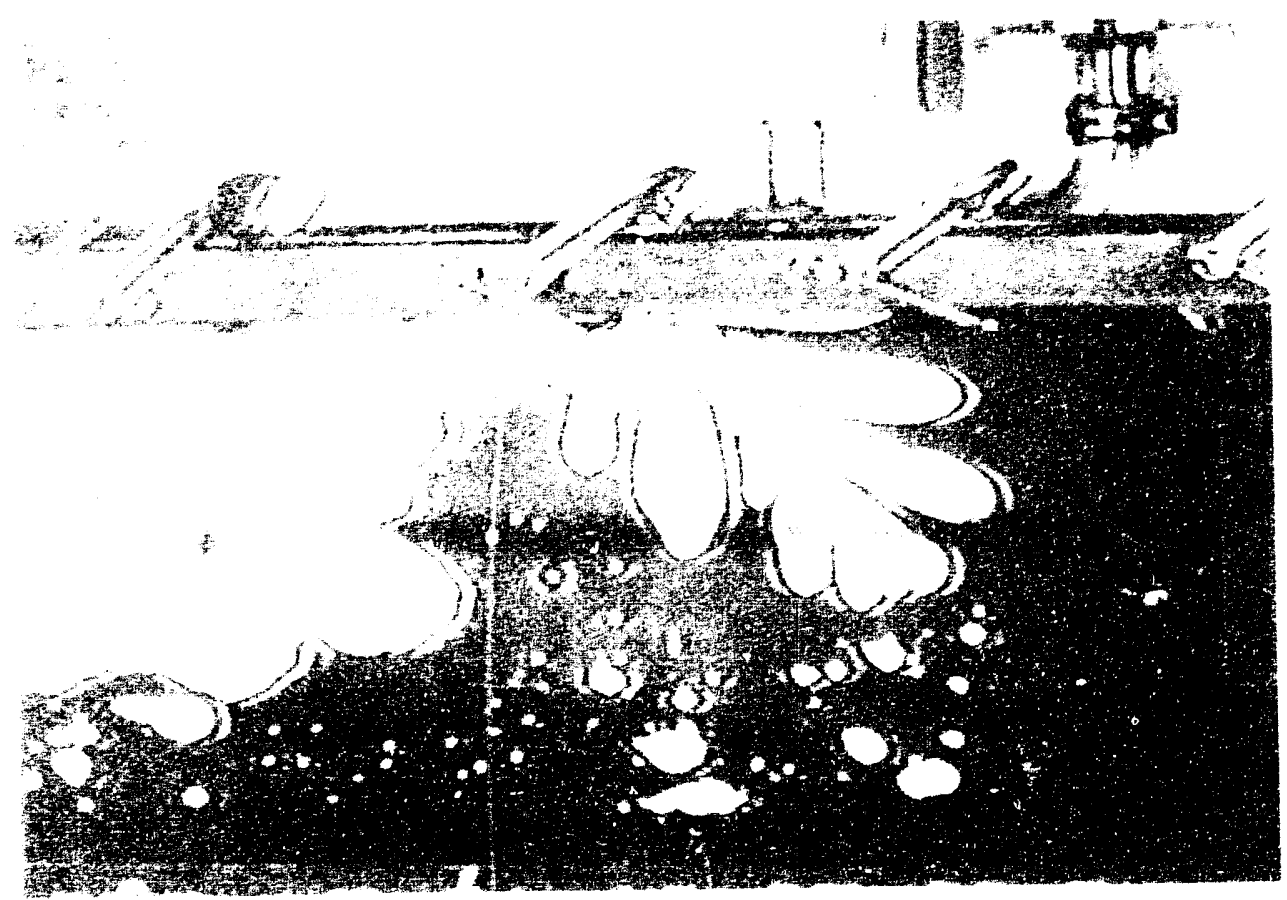

Figure 18: Steam gravity override 

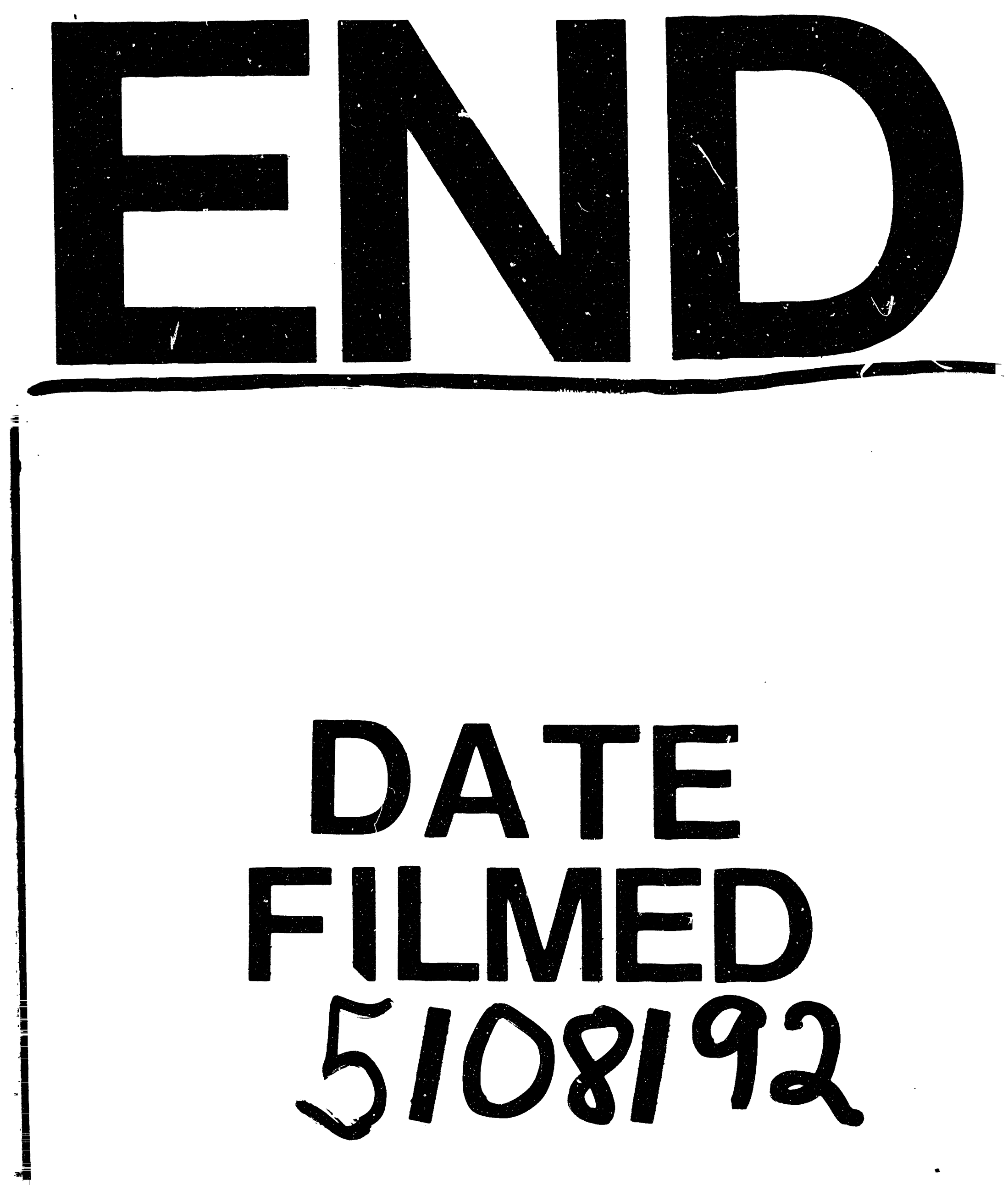